\title{
The association between the allelic state of $V p-1 B$ and pre-harvest sprouting tolerance in red-seeded hexaploid triticale
}

\author{
Mikhail Divashuk ${ }^{1}$, Nikolay Mayer ${ }^{2}$, Pavel Kroupin ${ }^{1}$, Valentina Rubets ${ }^{3}$, Vladimir Pylnev ${ }^{3}$, \\ Nguen Tkhi Tkhu Lin $^{3}$, Alexander Soloviev², Gennady Karlov ${ }^{1}$ \\ ${ }^{1}$ Center for Molecular Biotechnology, Russian State Agrarian University-Moscow Timiryazev Agricultural Academy, Moscow, Russia \\ ${ }^{2}$ Department of Genetics \& Biotechnology, Russian State Agrarian University-Moscow Timiryazev Agricultural Academy, Moscow, Russia \\ ${ }^{3}$ Department of Breeding and Seed Production of Field Crops, Russian State Agrarian University-Moscow Timiryazev Agricultural \\ Academy, Moscow, Russia \\ Email: divashuk@gmail.com
}

Received 3 November 2011; revised 9 December 2011; accepted 12 January 2012

\begin{abstract}
The core collection of red-seeded winter hexaploid triticale with different pre-harvest sprouting (PHS) resistance was evaluated for the allelic structure of the gene VIVIPAROUS-1B (Vp-1B) with STS molecular marker. The discovered structure of the collection has been found as follows: $50.0 \%$ and $41.7 \%$ of the collection carries the $V p-1 B a$ and $V p-1 B c$ alleles, respectively, while $8.3 \%$ possesses both of them. As a result of the seed color estimation, the collection was divided into two groups: with dark red seeds and light red seeds. The allele $V p-1 B c$ has appeared to be associated with PHS resistance while $V p-1 B a$ with PHS susceptibility in the triticale accessions with light red seeds only. The influence of the seed color and allelic state of $V p-1 B$ on PHS resistance in triticale is discussed.
\end{abstract}

Keywords: Preharvest Sprouting (PHS); Hexaploid Triticale; VIVIPAROUS-1B; Seed Color

\section{INTRODUCTION}

Triticale (X Triticosecale Wittmack) is the first artificial species developed by crossing wheat and rye. This crop was to combine the high yield and nutritional value of wheat with the hardiness and resistance of rye. However, triticale is characterized by some unfavorable traits. One of them is preharvest sprouting (PHS) which is typical for mild and humid climate. PHS results in considerable yield and grade losses [1]. To develop resistant cultivars is one of the most appropriate solutions of this serious problem. However, the selection for PHS resistance is complicated, because this trait is influenced by the genotype, environmental factors and their interaction [2].
Hence, the development of the reliable methods to select for PHS resistance is of great relevance for triticale breeders.

PHS is caused by the termination of dormancy in immature seeds in the ear which leads to the initiation of embryo growth. Dormancy is supposed to have evolved as a mechanism to escape adverse environmental conditions and intravarietal competition. In contrast, dormancy period was reduced by the domestication of species which was accompanied by the selection for uniform and rapid germination to achieve good stands [3]. Seed dormancy in wheat was shown to be associated with the level of abscisic and gibberellic acids, $\alpha$-amylase activity, structure of spike and awns and presence of water-soluble inhibitors of germination in the bracts of spikes and seed [1,4-6]. Since red seed color in wheat is associated with the higher level of dormancy [7], it has been used as a marker for PHS resistance. It might be due either to the tight genetic linkage or the pleiotropic effect of the genes responsible for grain color to PHS [8]. Another genetic factor with a major impact on seed dormancy is the gene VIVIPAROUS $(V p)$ which homologs $V p-1 A, V p-1 B$ and $V p-1 D$ were isolated and cloned in wheat [9-11]. The product of the gene was shown to be an incorrectly spliced transcriptional factor determining seed desiccation, dormancy and embryo sensitivity to abscisic acid. According to the recently obtained results, the level of the $V p-1 B$ transcription in the genotypes with $193 \mathrm{bp}$ insertion (the $V p-1 B b$ allele) and 83 bp deletion (the $V p-1 B b$ allele) is higher then in the wheat genotype without them (the $V p-1 B b$ allele) [11]. The analysis of the European wheat cultivars revealed that besides the mentioned alleles a new allele $V p-1 B d$ with 25 bp deletion also occurs [12]. The recent analyses of Chinese wheats revealed the new alleles, $V p-1 B f$ and $V p-1 B e$, 
which are associated with high seed dormancy $[13,14]$. The correlation found between the allelic state of $V p-1 B$ and the PHS in white kernel wheat can be applied in the marker-assisted selection for PHS resistance [11].

For efficient selection of triticale for PHS resistance the robust molecular markers are required. Since the $V p 1$ gene is present and expressed in triticale [15], the wheat DNA markers of this gene can be transferred to triticale. Recently, the influence of the allelic state of $V p-1 B$ to PHS has been shown in triticale [16].

The aim of this study is to analyze the allelic structure of the core collection of winter hexaploid triticale using STS molecular marker for gene $V p-1 B$ and the potential of its application in MAS-breeding of triticale to PHS resistance.

\section{MATERIALS AND METHODS}

\subsection{Plant Material}

The core collection of forty-eight winter triticale lines and cultivars susceptible and resistant to PHS were analyzed (Table 1, resistant accessions are highlighted with grey).

\subsection{Seed Color}

The intensity of red seed color was estimated according to the standard procedure with modifications by steeping seeds in 5\% solution of sodium hydroxide [17].

\subsection{DNA Extraction and PCR}

DNA was extracted from young leaves according to Bernatzky and Tanksley (1986) [18]. The site tagged sequence (STS) marker for the Viviparous-1B localized to chromosome 3B was used [11]. The PCR was carried out as described in Yang et al. (2007). Amplified PCR fragments were separated on a $1.5 \%$ agarose gel at $6 \mathrm{~V} / \mathrm{cm}$ in $0.5 \times$ TBE buffer, stained with ethidium bromide, and visualized using UV light. "100 bp ladder" (Fermentas) was applied as a size marker.

\subsection{Statistical Analysis}

To determine the strength of association between two qualitative traits the association coefficient of Pearson and contingency coefficient of Yule were calculated. The association is considered to be significant provided $\varphi \geq$ 0.5 or $\mathrm{Q} \geq 0.3$ [19].

\section{RESULTS}

\subsection{Seed Color and PHS}

The color of seed is known to be a polymeric trait because its intensity depends on the number of the dominant
Table 1. The allelic state of $V p-1 B$ gene of the winter triticale collection.

\begin{tabular}{|c|c|c|c|}
\hline \multicolumn{2}{|c|}{ Light-red seeded } & \multicolumn{2}{|c|}{ Dark-red seeded } \\
\hline triticale line & $\begin{array}{l}\text { the allelic state of } \\
\qquad V p-1 B\end{array}$ & triticale line & $\begin{array}{l}\text { the allelic state of } \\
\qquad V p-1 B\end{array}$ \\
\hline Soyuz & $V p-1 B c$ & Talva 100 & $V p-1 B a$ \\
\hline Hongor & $V p-1 B a$ & $214406 / 96$ & $V p-1 B c$ \\
\hline D-37 & $V p-1 B a$ & PRAG-D 246/1 & $V p-1 B a$ \\
\hline Mara & $V p-1 B a$ & Harmoniya & $V p-1 B a$ \\
\hline Tarasovskiy 1 & $V p-1 B c$ & Patriot & $V p-1 B a$ \\
\hline Marho & $V p-1 B c+V p-1 B a$ & Strelez & $V p-1 B a$ \\
\hline Avangard & $V p-1 B a$ & Amphidiploid 45 & $V p-1 B c$ \\
\hline Fidelio & $V p-1 B a$ & PRAG 488 & $V p-1 B c$ \\
\hline Ellada & $V p-1 B a$ & Grenadyor & $V p-1 B a$ \\
\hline Presto & $V p-1 B a$ & Germes & $V p-1 B a$ \\
\hline Konveyer & $V p-1 B a$ & Kapriz & $V p-1 B c$ \\
\hline Kentavr & $V p-1 B a$ & Kornet & $V p-1 B c$ \\
\hline TF 30 TL 1 & $V p-1 B a$ & Liniya 14 & $V p-1 B c$ \\
\hline Modul & $V p-1 B c+V p-1 B a$ & Strelna 11 & $V p-1 B c$ \\
\hline Talisman & $V p-1 B c$ & Rozovskiy 8 & $V p-1 B a+V p-1 B c$ \\
\hline Dao & $V p-1 B c$ & AD 4996 & $V p-1 B a$ \\
\hline E 775 & $V p-1 B c$ & TI 17 & $V p-1 B c$ \\
\hline AD 285 & $V p-1 B c$ & ADM 9 & $V p-1 B a$ \\
\hline Alamo & $V p-1 B a$ & KS - 88T & $V p-1 B c$ \\
\hline №222 & $V p-1 B c$ & $21759 / 97$ & $V p-1 B c$ \\
\hline Anthey & $V p-1 B c$ & Slavyanka & $V p-1 B a$ \\
\hline Vodoley & $V p-1 B c$ & Niklap & $V p-1 B a$ \\
\hline Kastus & $V p-1 B a$ & Polesskiy 7 & $V p-1 B c+V p-1 B a$ \\
\hline Victor 15 & $V p-1 B a$ & & \\
\hline Stavropolskiy 2 & $V p-1 B c$ & & \\
\hline
\end{tabular}

Note: resistant lines are highlighted with grey.

alleles and the expression of the transcriptional factors $[20,21]$. The studied core collection is represented by the red kernel triticale lines. Some research studies showed that the PHS resistance of red-seeded wheat is due not only to its linkage to the gene of seed color but also to the influence of the flavonoids in the seed coat on seed dormancy. In our case we assumed that the level of them may also influence the PHS resistance in winter triticale. To determine the level of the flavonoids the seed color has been assessed. As a result, it has been revealed that the studied collection differs in tint of red color of the 
seed and consists of twenty-five light and twenty-three dark red seeded triticale (Table 1). Thereafter, the strength of the association between the PHS resistance and seed color was estimated using contingency coefficient of Pearson and association coefficient of Yule [19]. As a result, the values of the coefficients did not exceed 0.3 and 0.5 , respectively, therefore, the association is not significant.

\subsection{The Allelic State of $V p-1 B$}

The STS marker [11] was applied to find out the $V p-1 B$ allelic structure of the core collection. The $V p-1 B a$ allele has been detected in twenty-four triticale lines $(50.0 \%)$, the $V p-1 B c$ allele has been revealed in twenty lines $(41.7 \%)$, both alleles has been found in four lines $(8.3 \%)$ (Table 1). No $V p-1 B b, V p-1 B d, V p-1 B e$ or $V p$ - $1 B f$ alleles has been found in the collection.

The influence of the allelic state of $V p-1 B$ on PHS resistance was shown only in white-seeded wheat [11]. By analogy, we estimated the significance of the association between the PHS resistance and allelic state of $V p-1 B$ in the triticale lines with dark red and light red seeds. No statistically significant association has been found in the dark red-seeded lines. At the same time, the association has appeared to be significant in the light red-seeded lines (the contingency coefficient is 0.37 and the association coefficient is 0.67 ).

\section{DISCUSSION}

In our study for the first time the association between the PHS resistance, allelic state of $V p-1 B$ and intensity of seed color in winter triticale was analyzed.

It has been revealed that $50.0 \%$ of the analyzed triticale lines have $V p-1 B a$ allele, $41.7 \%$ carry the $V p-1 B c$ allele, $8.3 \%$ of the collection possesses both of them (Table 1). The results are in accordance with that obtained in wheat. The alleles $V p-1 B a$ and $V p-1 B c$ were shown to be the most widespread in Chinese and European wheat as well $[12,14,22,23]$. In our collection of winter triticale no $V p-1 B b, V p-1 B d, V p-1 B e$ or $V p-1 B f$ alleles have been found. These alleles appear relatively rare in wheat with the exception for $V p-1 B d$ in the European collection of wheat [12]. Therefore, in the whole, the allelic structure of the studied triticale collection and different wheat collections are rather similar.

The color of seed in wheat and rye is determined by the accumulation of the phenolic products of the flavonoid pathway. The polyphenolic compounds are shown to be the inhibitors of germination [24,25]. The product of the $V p$ gene responsible for the embryo sensitivity to ABA, embryo maturation and its transition to dormancy [26] is also known to be involved in the flavonoid pathway [27]. Moreover, flavonoid synthesis genes control- ling seed color, $V p$-1 and other transcriptional factors of the flavonoid pathway are localized to the distal region of the third homoeological group chromosome in wheat $[21,28]$. So, the factors determining PHS resistance and seed color in wheat and rye demonstrate tight interaction at biochemical pathways and genetic linkage. The role of the phenolic compounds in caryopsis as PHS resistance regulator in triticale was shown by Weidner et al. (1999) [29]. At the same time, the first studies did not reveal any association between $V p-1$ expression and PHS resistance in triticale [30]. The tint of red color of the seed and PHS resistance, shown at our work, in triticale are likely to be a result of multiple interactions between the products of the flavonoid pathways and various transcriptional factors including $V p-1$ analogs of wheat and rye genomes. Nevertheless, the association between PHS resistance and $V p-1 B$ allelic state in light red-seeded triticale resembles the same as in white-seeded wheat. This allows suggesting that the similar biochemical and genetic mechanisms conferring PHS resistance are involved in both cases. The result of this mechanism is likely to be the greater contribution of $V p-1 B$ to PHS resistance at the lower level of the compounds determining seed color or/ and inhibition of germination.

In conclusion, the allelic state of $V p-1 B$ has been found to be associated with the PHS resistance in the light red-seeded lines of winter triticale: $V p-1 B c$ and $V p-1 B a$ alleles are linked with PHS resistance and susceptibility, respectively. This statement is in agreement with the results obtained on the light red-seeded sister lines F5 (I3) obtained from cross of the resistant and non resistant to PHS triticale lines [16]. At the same time, this association has not been found in the dark redseeded triticale lines. The STS molecular marker for $V p-1 B$ alleles can be applied in marker assisted selection of winter triticale. However, its application can be limited to the lines with light red seeds only.

\section{ACKNOWLEDGEMENTS}

The work was supported by the Federal Target Program "Researches and developments on priority directions in the development of scientific-technological complex of Russia in 2007-2013", state contract no. 16.518.11.7089. "The conduction of scientific research with the use of unique devices "The complex for conducting interdisciplinary studies in the sphere of comparative and functional plant genomics".

\section{REFERENCES}

[1] Moś, M. and Wójtowicz, T. (2004) The effect of seed sprouting damage on field emergence and yield of spring triticale. Journal of Central European Agriculture, 5, 251258.

[2] Herrmann, M. (2007) A diallel analysis of various traits in winter triticale. Plant Breeding, 126, 19-23. 
doi:10.1111/j.1439-0523.2007.01323.x

[3] Finkelstein, R., Reeves, W., Ariizumi, T. and Steber, C. (2008) Molecular aspects of seed dormancy. Annual Review of Plant Biology, 59, 387-415. doi:10.1146/annurev.arplant.59.032607.092740

[4] Derera, N.F. and Bhatt, G.M. (1980) Germination inhibition of the bracts in relation to preharvest sprouting tolerance in wheat. Cereal Research Communications, 8, 199-201. doi:10.4141/cjps89-084

[5] Paterson, A.H., Sorrells, M.E. and Obendorf, R.L. (1989) Methods of evaluation for preharvest sprouting resistance in wheat breeding programs. Canadian Journal of Plant Science, 69, 681-689.

[6] Gatford, K.T., Eastwood, R.F. and Halloran G.M. (2002) Germination inhibitors in bracts surrounding the grain of Triticum tauschii. Functional Plant Biology, 29, 881-890. doi:10.1071/PP01011

[7] Torada, A. and Amano Y. (2002) Effect of seed coat color on seed dormancy in different environments. Euphytica, 126, 99-105. doi:10.1023/A:1019603201883

[8] Kuraparthy, V., Sood, S. and Gill, B.S. (2008) Targeted genomic mapping of a red seed color gene (R-A1) in wheat. Crop Science, 48, 37-48. doi:10.2135/cropsci2007.08.0488tpg

[9] Nakamura, S. and Toyama, T. (2001) Isolation of a VP1 homologue from wheat and analysis of its expression in embryos of dormant and non-dormant cultivars. Journal of Experimental Botany, 52, 875-876. doi:10.1093/jexbot/52.362.1952

[10] Wilkinson, M., Lenton, J. and Holdsworth, M. (2005) Transcripts of Vp-1 homoeologues are alternatively spliced within the Triticeae tribe. Euphytica, 143, 243-246. doi:10.1007/s10681-005-7856-2

[11] Yang, Y., Ma, Y.Z., Xu, Z.S., Chen, X.M., He, Z.H., Yu, Z., Wilkinson, M., Jones, H.D., Shewry, P.R. and Xia, L.Q. (2007) Isolation and characterization of Viviparous1 genes in wheat cultivars with distinct ABA sensitivity and pre-harvest sprouting tolerance. Journal of Experimental Botany, 58, 2863-2871. doi:10.1093/jxb/erm073

[12] Xia, L.Q., Ganal, M.W., Shewry, P.R., He, Z.H., Yang, Y., Röder, M.S. (2008) Exploiting the diversity of Viviparous-1 gene associated with pre-harvest sprouting tolerance in European wheat varieties. Euphytica, 159, 411417. doi:10.1007/s10681-007-9576-2

[13] Chang, C., Feng, J.M., Si, H.Q., Yin, B., Zhang, H.P. and Ma, C.X. (2010a) Validating a novel allele of viviparous$1(V p-1 B f)$ associated with high seed dormancy of Chinese wheat landrace, Wanxianbaimaizi. Molecular Breeding, 25, 517-525. doi:10.1007/s11032-009-9350-3

[14] Chang, C., Zhang, H.P., Feng, J.M., Yin, B., Si, H.Q., Ma, C.X. (2010b) Identifying alleles of Viviparous-1B associated with pre-harvest sprouting in micro-core collections of Chinese wheat germplasm. Molecular Breeding, 25, 481-490. doi:10.1007/s11032-009-9346-Z

[15] De Laethauwer, S., Messens, K., Derycke, V. et al. (2006) An approach to developing a marker assisted selection system for tolerance to pre-harvest sprouting in Triticale. Proceedings of 6th International Triticale Symposium,
South Africa, Stellenbosch, 3-7 September 2006, 39-44.

[16] Maier, N.K., Divashuk, M.G., Kroupin, P.Yu and Soloviev, A.A. (2009) Influence of VIVIPAROUS-1 allelic state on pre-harvest sprouting in spring triticale. Izvestija Timirjazevskoj akademii, 4, 138-142 (in Russian).

[17] Chemelar, F. and Mostovoj K. (1938) Application of some older and introduction of new method for testing genuineness of variety in the laboratory. Proceedings of International Seed Testing Association, 10, 68-74.

[18] Bernatzky, R. and Tanksley, S.D. (1986) Toward a saturated linkage map in tomato based on isozyme and random cDNA sequences. Genetics, 112, 887-898.

[19] Das, D. and Das. A. (2008) Statistics in biology \& psychology. Academic Publishers, Kolkata, 187-193.

[20] Nilson-Ehle H. (1914) Zur Kenntnis der mit der keimungsphysiologie des weizens in zusammenhang stehenden inneren faktoren. Zeitschrift für Planzenzüctung, 2, 153-187.

[21] Himi, E. and Noda, K. (2005) Red grain color gene (R) of wheat is a Myb-type transcription factor. Euphytica, 143, 239-242. doi:10.1007/s10681-005-7854-4

[22] Yang, Y., Zhao, X.L., Zhang, Y., Chen, X.M., He, Z.H., Yu, Z. and Xia, L.Q. (2008) Evaluation and validation of four molecular markers associated with pre-harvest sprouting tolerance in Chinese wheats. Acta Agronomica Sinica, 34, 17-24 (in Chinese). doi:10.1016/S1875-2780(08)60002-4

[23] Yang, Y., Chen, X.M., He, Z.H., Röder, M. and Xia, L.Q. (2009) Distribution of Vp-1 alleles in Chinese whitegrained landraces, historical and current wheat cultivars. Cereal Research Communications, 37, 169-177. doi:10.1556/CRC.37.2009.2.3

[24] Weidner, S., Amarowicz, R., Karamac, M. and Fraczek, E. (2000) Changes in endogenous phenolic acids during development of Secale cereale caryopses and after dehydration treatment of unripe rye grains. Plant Physiology and Biochemistry, 38, 595-602. doi:10.1016/S0981-9428(00)00774-9

[25] Kong, L., Wang, F., Si, J., Feng B., Li S. (2008) Watersoluble phenolic compounds in the coat control germination and peroxidase reactivation in Triticum aestivum seeds. Plant Growth Regulation, 56, 275-283. doi:10.1007/s10725-008-9307-2

[26] McCarty, D.R. (1995) Genetic control and integration of maturation and germination pathways in seed development. Annual Review of Plant Physiology and Plant Molecular Biology, 46, 71-93.

doi:10.1146/annurev.pp.46.060195.000443

[27] Suzuki, M., Ketterling, M.G., Li, Q.B., McMarty, D.R. (2003) Viviparous 1 alters global gene expression patterns through regulation of abscisic acid signaling. Plant Physiology, 132, 1664-1677. doi:10.1104/pp.103.022475

[28] Groos, C., Gay, G., Perretant, M.R., Gervais, L., Bernard, M., Dedryver, F. and Charmet, G. (2002) Study of the relationship between pre-harvest sprouting and grain color by quantitative trait loci analysis in a white 9 red grain breadwheat cross. Theoretical and Applied Genetics, 104, 39-47. doi:10.1007/s001220200004 
[29] Weidner, S., Amarowicz, R., Karamać, M. and Dąbrowski, G. (1999) Phenolic acids in caryopses of two cultivars of wheat, rye and triticale that display different resistance to pre-harvest sprouting. European Food Research and Technology, 210, 109-113. doi:10.1007/s002170050544
[30] De Laethauwer, S., Reheul, D., De Riek, J. and Haesaert, G. (2009) The use of Vp-1 in real time RT-PCR to select for pre-harvest sprouting tolerance in triticale. Euphytica, 168, 379-384. doi:10.1007/s10681-009-9930-7 